\title{
A Multiobjective Optimization Model of Production-Sourcing for Sustainable Supply Chain with Consideration of Social, Environmental, and Economic Factors
}

\author{
Zhixiang Chen ${ }^{1}$ and Svenja Andresen ${ }^{2}$ \\ ${ }^{1}$ School of Business, Sun Yat-sen University, Guangzhou 510275, China \\ ${ }^{2}$ WFI, Ingolstadt School of Management, Catholic University of Eichstätt-Ingolstadt, 85072 Eichstätt, Germany \\ Correspondence should be addressed to Zhixiang Chen; mnsczx@mail.sysu.edu.cn
}

Received 20 January 2014; Revised 31 March 2014; Accepted 4 April 2014; Published 27 April 2014

Academic Editor: Hamid Reza Karimi

Copyright (C) 2014 Z. Chen and S. Andresen. This is an open access article distributed under the Creative Commons Attribution License, which permits unrestricted use, distribution, and reproduction in any medium, provided the original work is properly cited.

This paper incorporates the three pillars of sustainability-economic, environmental, and social dimensions-into a supply chain. A multiobjective programming model which jointly minimizes costs, emissions, and employee injuries in a supply chain is first constructed. Using the weighted-sum approach with weights setting by the analytic hierarchy process (AHP), the model is solved by normalization of the minima of the three objectives. A numerical example is conducted to test the model. The results show that it is indeed possible to integrate environmental and social metrics in supply chain system optimization. Multiobjective optimization can balance the social, environmental, and economic performance. This paper presents a new multidimension perspective for optimizing supply chain; it will inspire practitioners to change their decision ideas and improve supply chain sustainability.

\section{Introduction}

Sustainable development is becoming a world-wide hot topic in academics and practice. "If everyone used energy and resources the same way we do in the Western World, we would need three more earths at least. And we have only one." [1]. The former Minister for Sustainable Development in Sweden addressed one of the major challenges we have to face in the 21st century-the scarcity of resources. More and more countries, institutions, and businesses recognize that the world population has to change its behavior to tackle problems that might easily become or already are constraints to international growth. In a report for the OECD, Strange and Bayley [2] draw up a great past in terms of economic growth with incomes having increased eightfold since 1820, but they also suggest that there are "clouds on the horizon." Salim [3] states that "unsustainable development has degraded and polluted the environment in such a way that it acts now as the major constraint followed by social inequity that limits the implementation of perpetual growth." The bad effect of pollution, also on economic wealth, has been examined especially in the context of climate change. The Climate Vulnerability Monitor by the NGO DARA reveals the impact of global warming on every aspect of life [4]. It estimates that in 2010 the global economy has to bear total losses of around 1.2 trillion dollars due to the carbon emission and climate change. Different from other consequences, those losses are also significant in the industrialized world [4].

There are other driving factors, such as customer awareness, media interference or governmental regulations that push the development of sustainable solutions [5]. For example, in 2005, the Emissions Trading System had been launched in the European Union. It covers more than 11,000 power stations and industrial plants in 31 countries. This "cap-and-trade" approach gives high-emitting industry sectors the choice to either cut down on pollution or to bear the cost of buying emission allowances [6]. This is definitely an incentive for European companies to pursue greener production. Besides the environmental problem, corporate social responsibility is also a growing issue. In 2012, a TV news report about the working conditions in manufacturing sites for jeans in China triggered countrywide 
discussions in Germany [7]. And this is just one media coverage amongst many. There are also many other events of media interfering sustainable development, such as, the German magazine "Wirtschaftswoche" denounced textile factories in Bangladesh [8], the US newspaper "The New York Times" wrote about the human costs of an iPad [9], and, even in China, the "China Daily" called for an improvement of migrant workers' situation [10]. Nowadays, consumers thereby are becoming more and more concerned about the sustainability of companies' activities.

Under this international background of sustainable development, sustainability management becomes increasingly important, and supply chain management surely cannot be excluded from this stream of sustainable development. On the contrary, supply chain managers are significantly involved in companies' operations and bear more and more responsibilities in essential decision making processes, such as the selection of suppliers, transport modes, or production methods during sustainable manufacturing [11]. In academics, sustainable supply chain management (SSCM) has become a new hot topic for research; more and more authors are researching the problem of sustainable supply chain strategy and operations management.

While there is an abundance of supply chain models that integrates economic and environmental goals concerning green supply chain (e.g., [12-16]), there is only a few of them considering the social layer issues (e.g., $[17,18]$ ). Carter and Rogers [19] also criticize that general management as well as the operations management literature often focuses on the ecological dimension of sustainability and neglects social aspects.

In the literature of the area of production and logistics system optimization, there are some authors who have studied the complex production-supply logistics systems; AitAlla et al. [20] study the robust production planning in an apparel industry under demand uncertainty via conditional value at risk. Karimi et al. [21] study a class of production networks of autonomous work systems with time varying delays in capacity changes. Mehrsai et al. [22] address a pull-push flow strategy in a supply network and propose a novel solution for optimizing the pull side employing conwip system using metaheuristic and fuzzy system optimization method. Mehrsai et al. [23] study production-logistics system using simulation method, in which a learning autonomous pallets' concept is used in a discrete simulation model to analyze and compare several decentralized control strategies.

However, all those studies do not consider the social objectives. Using different previous research, in this paper, we take an iron and steel factory as case background, considering the above three sustainable factors, study the complex multiobjective optimization model of productionsourcing logistics system. In this model, several raw materials are supplied from different suppliers, and then the iron and steel factory produces products to meet customers demand. Through constructing a multiobjective programming model by concurrently considering social, environmental, and economic factors, we demonstrate the benefit of sustainable supply chain system optimization based on multiple factors instead of single economic objective.
This paper is organized as follows. First, a definition of sustainability in general and sustainable supply chain management in particular is developed based on the literature review. Then, based on existing research, an optimization model of sustainable supply chain system based on multiobjective programming approach is constructed and, thirdly, the corresponding solution method is developed. Fourthly, a numerical example is used to demonstrate the application of the model. At last, conclusion and future research directions are summarized.

\section{Definition and Framework of Sustainable Supply Chain}

(1) Sustainability. The idea of sustainability goes back to the mid-ages. In 1713, Hanns Carl von Carlowitz, head of the Royal Mining Office in the Kingdom of Saxony, in order to meet the challenge of a predicted shortage of timber-the key resource of the time-requested that the number of trees that are cut down may not exceed the amount of new trees growing [24]. This idea tells that the nature resource of the earth is limited, and human being should moderately utilize the nature resource.

In modern age, the discussion about sustainability was initiated in 1972 when the Club of Rome published its first report "Limits to growth" [5]. One of the milestones in the development of the sustainability definition was a UN (United Nations) report commonly known as Brundtland Report, and the original name of the report was "Our common future" [25]. It is notable to mention that the former Norwegian Prime Minister, Gro Harlem Brundtland, shaped not only the name of this memorandum but the whole definition of sustainability for years to come [25]. Even today, more than 30 years later, "development that meets the need of the present without compromising the ability of future generations to meet their needs" (World Commission on Environment and Development [25]) is still the basis for most definitions of sustainability.

One of the most famous literatures when it comes to sustainability is Elkington's book "Cannibals with Forks: The Triple Bottom Line of the 21st Century" [26]. He compares sustainability to a fork with three prongs. The three prongs stand for the economic, environmental, and social performance of an organization. The idea of the triple bottom line promotes the simultaneous optimization of all three dimensions. Carter and Rogers have transformed this idea into a figure (see Figure 1) and conclude that "there are activities that organizations can engage in which not only positively affect the natural environment and society, but which also result in long-term economic benefits and competitive advantage for the firm" [19].

These three aspects of sustainability are sometimes also called 3 Ps: profit, planet, and people [5]. Dyllick and Hockerts [27] describe the triple bottom line as 3 different types of capital: economic, natural, and social capital. In order to reach corporate sustainability, they conclude that all three types of capital have to be optimized. 


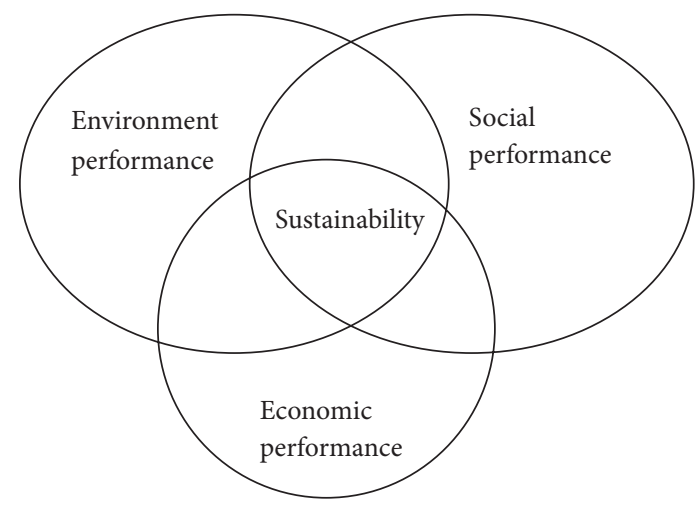

FIgURE 1: The triple bottom line of sustainability [19].

Nowadays, the notion of sustainability has been defined on a macroeconomic basis as well as in the sense of corporate sustainability [26, 27]. In this paper, we will base on the idea of sustainability to construct the optimization model of sustainable supply chain management.

(2) Sustainable Supply Chain Management. There is no consensus definition on the sustainable supply chain management. Carter and Rogers [19] define sustainable supply chain management (SSCM) as follows.

The strategic, transparent integration and achievement of an organization's social, environmental, and economic goals in the systemic coordination of key inter-organizational business processes for improving the long term economic performance of the individual company and its supply chains.

Tang and Zhou [28] use the PPP (profit, people, and planet) approach to construct a sustainable supply chain model (see Figure 2). In Figure 2, the economic dimension is depicted by the blue arrows (i.e., the central part of the figure, from the box of "producers" to the box of "supply chain" and the box of "consumers"), the green arrow represents the environmental problems (i.e., from the box of "wastes and emissions" to the box of "natural resource" in the figure) and the red arrow stands for social facets (i.e., from the box of "producers" to the box of "consumers").

All of the SSCM definitions have one thing in common: they emphasize the necessity to simultaneously consider all three dimensions within the supply chain; that is, while considering the economic performance of supply chain, improving social and environmental impact also has to be considered. Cetinkaya et al. [29] employ a three-dimension metrics system to describe the sustainability, that is, social, economic, and environmental dimensions, and each of the dimensions is broken down into other three subdimensions (see Figure 3). They state that an improvement in any of these subdimensions, without a negative effect on another subdimension, will ultimately lead to a more sustainable supply chain.

In order to make the sustainable supply chain quantifiable, in this paper, we will follow the approach of Cetinkaya et al. [29], as it is necessary to find and categorize metrics. According to this framework, we will construct a series of metrics of sustainable supply chain, and then under

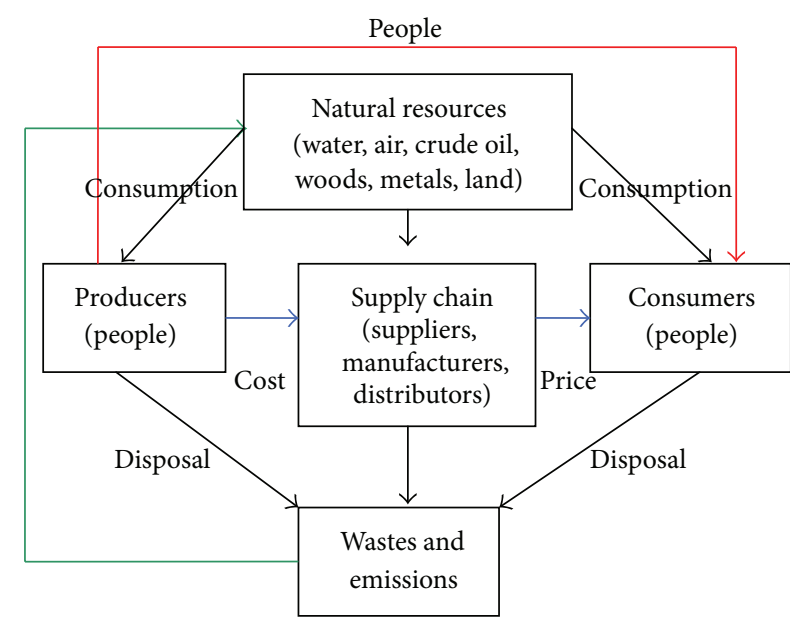

Figure 2: Supply chain integrated in the PPP ecosystem [28].

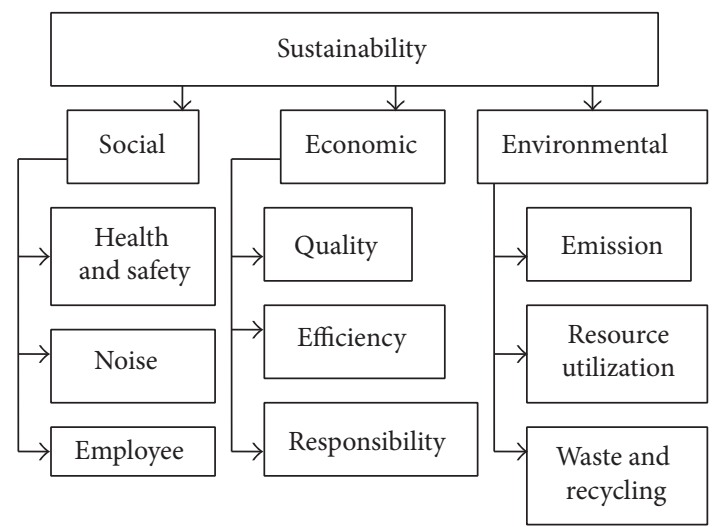

FIgURE 3: Metric dimensions and subdimensions of sustainability [29].

these three objective dimensions-social, economic, and environmental dimensions, to construct a multiobjective programming model.

\section{Problem Definition and Modeling}

Before applying the mathematical optimization model, we first define the assumptions of the supply chain and then formulate the optimization problem.

3.1. Supply Chain Model and Problem Definition. The optimization problem proposed in this paper is simulated from the production facility's perspective with only one period of time under consideration. In the model, a production facility produces one type of output, which is shipped to a group of customers. The raw materials are sourced from a finite number of suppliers. The suppliers ship the raw materials via different transport modes to the production facility.

For the optimization of the supply chain, several assumptions are made as follows.

(1) The supply is organized in a just-in-time manner, so that the effect of incoming items inventory can be neglected. 
(2) The ordered quantities of all raw materials will meet the needs of the production.

(3) There is more than one type of raw materials sourced from several suppliers.

(4) The production facility, suppliers, and transportation options have capacity constraints.

(5) All suppliers together can fulfill the ordered quantities needed for production and meet the demand of customers.

(6) The demand of the customers is known and the production facility is able to satisfy the demand.

(7) Outgoing items inventory will remain insignificantly small and is therefore neglected.

(8) Transportation costs depend on the distance from suppliers to production facility, as well as on the quantity shipped.

(9) Production emissions depend on the chosen production method, as well as the produced quantity, while transportation emissions are dependent on the shipped quantity of the respective material and the distance from the suppliers to the production facility.

The proposed model gives answers to the following questions (established as decision variables).

(i) How much quantity of the respective raw material should be ordered from which supplier?

(ii) How much quantity of a raw material should be shipped using what transport mode from the respective supplier to the production facility?

(iii) Which production method should be chosen?

Based on viewpoint of sustainable supply chain, the optimization model of supply chain includes three objectives: economical, environmental, and social objectives. Subsequently, the three dimensions should be optimized simultaneously. According to the subdimensions of a sustainable supply chain presented in Cetinkaya et al. [29], several metrics can be chosen to quantify the three aspects under consideration. Due to the limited space of the paper, therefore, for each dimension, only one metric will be selected to measure the supply chain's performance in the respective field. For the sake of computation convenience, the chosen indicators should be simple, understandable, easy to reproduce, comparable, complementary to regulatory programs, costeffective in data collection, stackable and scalable, useful as a management tool, and protective of company information [30].

The first objective is to achieve economic sustainability. The three subdimensions of economic sustainability are quality, efficiency, and responsiveness. As for Cetinkaya et al.'s [29] statement, efficiency is "the most familiar dimension for all managers" (page 61). This is also reflected by Székely and Knirsch [30], who study the metrics used in 20 different companies' annual reports and sustainability reports. There are several measures for efficiency: utilization, productivity, cost reduction, and service level. For the purpose of this paper and under the assumptions, minimizing costs will be chosen to represent the economic dimension. The cost of the production facility is composed of production costs, transportation costs, and material costs for the sourced raw materials.

The environmental dimension consists of the following components: emissions, natural resources utilization and waste, and recycling [29]. Tang and Zhou [28], as well as Dekker et al. [11], pinpoint that one of the most important ways to estimate environmental impact is the measurement of emissions and pollution. This is the fact due to "more stringent government regulations and increasing awareness of environmental protection among consumers and society" ([28], page 591). The two major sources of emission in supply chains are production operations and transportation. Therefore the environmental objective in the model will be assessed using the emissions of the production method and the transportation options. As shown by Daniel et al. [31], pollution can be classified into three categories: water, air, and soil pollution. If applicable, harm to all three areas should be considered.

Last but not least, probably the most difficult part is the social dimension. Health and safety, employees, and noise are the three subdimensions determined by Cetinkaya et al. [29]. One of the most commonly adapted metric in this field is the accident and illness number, or rather the accident/illness number in relation to working hours [30]. This measure will be taken as a basis and modified to accommodate the severity of different accidents and illnesses.

3.2. Mathematical Formulation of the Model. Having completed the general model description and problem introduction, we can now formulate the problem. At first, indices and variables will be defined, followed by the construction of the objective functions and the constraint functions.

\subsubsection{Indices and Notations}

Indices

$$
\begin{aligned}
& i(1, \ldots, I): \text { supplier; } \\
& r(1, \ldots, R): \text { raw material; } \\
& m(1, \ldots, M): \text { production method; } \\
& t(1, \ldots, T): \text { transport mode; } \\
& p(1, \ldots, P): \text { pollutant; } \\
& n(1, \ldots, N): \text { severity class of injury. }
\end{aligned}
$$

\section{Decision Variables}

$Q_{i}^{r}$ : quantity of raw material $r$ bought from supplier $i$; $\mathrm{PM}_{m}: 1$, if production method $m$ is chosen, 0 otherwise;

$\mathrm{TQ}_{t i}^{r}$ : quantity of raw material $r$, shipped from supplier $i$, using transport mode $t$. 


\section{Cost Parameters}

$C_{i}^{r}$ : cost per unit of raw material $r$ bought from supplier $i$;

$H_{m}$ : hours of work for one unit of product under production method $m$;

$L$ : labor cost per hour;

$\mathrm{DP}_{m}$ : depreciation per unit of product, if production method $m$ is chosen;

$\mathrm{UC}_{m}$ : utility cost per unit of product, if production method $m$ is chosen;

$X$ : quantity of products produced in units (equals demand of product);

$\mathrm{TC}_{t i}^{r}$ : cost for transportation per kilometer of one unit of raw material $r$ with transport mode $t$ from supplier $i$;

$d_{i}$ : distance from supplier $i$ to the production facility.

\section{Pollution Parameters}

$A_{t}^{p r}$ : pollution through pollutant $p$ per $\mathrm{km}$ and unit of raw material $r$, if transport mode $t$ is chosen;

$A_{m}^{p}$ : pollution through pollutant $p$ per unit of product, if production method $m$ is chosen.

\section{Safety Parameters}

$I_{m}^{n}$ : number of injuries in severity class $n$, if production method $m$ is chosen.

\section{Constraint Parameters}

$\mathrm{PCA}_{m}$ : capacity of production method $m$;

$\mathrm{TCA}_{t i}^{r}$ : capacity of transportation mode $t$ for raw material $r$, on route from supplier $i$ to the production facility;

$$
\begin{aligned}
& \operatorname{SCA}_{i}^{r} \text { : capacity of supplier } i \text { for raw material } r \text {; } \\
& U_{m}^{r} \text { : usage of resource } r \text { in production method } m \text { for } \\
& \text { one unit of product. }
\end{aligned}
$$

\subsubsection{Objective Functions}

(1) Economic Objective. As mentioned above, the economic objective will be included by minimizing the costs within the supply chain. The production costs are assumed to be mainly labor costs, depreciation costs (for the machinery), and utility costs. That is,
Minimize $F_{1}=$ Material cost + Production cost + Transportation cost,

$$
\begin{aligned}
\min F_{1}= & \sum_{r=1}^{R} \sum_{i=1}^{I} C_{i}^{r} Q_{i}^{r} \\
& +\sum_{m=1}^{M}\left(H_{m} X L+\mathrm{DP}_{m} X+\mathrm{UC}_{m} X\right) \mathrm{PM}_{m} \\
& +\sum_{i=1}^{I} \sum_{r=1}^{R} \sum_{t=1}^{T} \mathrm{TC}_{t i}^{r} d_{i} \mathrm{TQ}_{t i}^{r} .
\end{aligned}
$$

(2) Environmental Objective. The environmental dimension is optimized by minimizing emissions within the supply chain, that is, pollution created by transportation and by production. That is,

Minimize $F_{2}=$ Transportation emissions + Production emissions,

$$
\min F_{2}=\sum_{p=1}^{P} \sum_{r=1}^{R} \sum_{t=1}^{T} \sum_{i=1}^{I} A_{t}^{p r} \mathrm{TQ}_{t i}^{r} d_{i}+\sum_{m=1}^{M} \sum_{p=1}^{P} A_{m}^{p} X \mathrm{PM}_{m}
$$

(3) Social Objective. The foundation for the social objective function is the injury/illness incidence rate used by the American Bureau of Labor Statistics [32], which is formulated as

Incidence rate $=($ Number of injuries and illnesses $*$ 200,000)/Employee hours worked.

The 200,000 hours in the formula represents the equivalent of 100 employees working 40 hours per week, 50 weeks per year, and provides the standard base for the incidence rates. The formula includes all nonfatal work-related injuries and illnesses that are recordable.

For the purpose of this paper, the formula will be amended to include the severity of injuries and illnesses. To achieve this, it is proposed that all injuries/illnesses will be categorized according to the days absent from work. The injuries/illnesses that are less severe will be given a low severity level, while the highest rank will be work-related fatalities. For example injuries/illnesses could be ranked as follows (see Table 1).

To represent the severity of the injuries/illnesses, an exponential function will be applied. The exponential function can show that the higher the class, the more unfavorable an incidence. In this way, the model can guide the decision maker (in our case the company) to employ production methods that will especially decrease the danger of severe injuries or illnesses. On the other hand, minor incidences become acceptable to a certain degree. Largely those small accidents (like cuts or tripping over) are most probably not even preventable.

In the example, cases that are in category 4 will therefore be included in the injury/illness incidence rate with factor 1 , while incidents in lower classes are less weighted and occurrences in higher categories become more important (see Table 2). 
TABLE 1: Severity classes of work-related injuries/illnesses.

\begin{tabular}{ll}
\hline$n$ & Severity class description \\
\hline 1 & Less than a week absent from work \\
2 & Less than a month absent from work \\
3 & Less than 3 months absent from work \\
4 & Less than 6 months absent from work \\
5 & Less than a year absent from work \\
6 & Occupational disability (the person will not be able to \\
7 & work in the previous job again) \\
\hline
\end{tabular}

TABLE 2: The exponential severity function.

\begin{tabular}{ccc}
\hline$n$ & $n-\left(\sum n\right) / N$ & $e^{n-\left(\sum n\right) / N}$ \\
\hline 1 & -3 & 0.049787 \\
2 & -2 & 0.135335 \\
3 & -1 & 0.367879 \\
4 & 0 & 1 \\
5 & 1 & 2.718282 \\
6 & 2 & 7.389056 \\
7 & 3 & 20.08554 \\
\hline
\end{tabular}

According to this, the third objective function can be modeled, which includes the rephrased injury/illness incidence rate as follows:

$$
\min F_{3}=\sum_{m=1}^{M} \mathrm{PM}_{m} \sum_{n=1}^{N} e^{n-\sum n / N} I_{m}^{n} \frac{200,000}{H_{m} X}
$$

\subsubsection{Constraints. Consider that}

$$
\begin{gathered}
\sum_{i=1}^{I} \mathrm{Q}_{i}^{r}=\sum_{m=1}^{M} \mathrm{PM}_{m} U_{m}^{r} X, \quad \forall r, \\
\sum_{m=1}^{M} \mathrm{PM}_{m} \mathrm{PCA}_{m} \geq X, \\
\mathrm{Q}_{i}^{r}=\sum_{t=1}^{T} \mathrm{TQ}_{t i}^{r}, \quad \forall r, i, \\
\sum_{t=1}^{T} \sum_{i=1}^{I} \mathrm{TQ}_{t i}^{r}=\sum_{i=1}^{I} \mathrm{Q}_{i}^{r}, \\
\mathrm{TCA}_{t i}^{r} \geq \mathrm{TQ}_{t i}^{r}, \quad \forall r, i, t, \\
\mathrm{SCA}_{i}^{r} \geq Q_{i}^{r}, \quad \forall r, i, \\
\sum_{i=1}^{I} \mathrm{SCA}_{i}^{r} \geq \sum_{i=1}^{I} \mathrm{Q}_{i}^{r}, \quad \forall r, \\
\mathrm{PM}_{m}=\{0,1\}, \quad \forall m,
\end{gathered}
$$

$$
\begin{gathered}
\mathrm{Q}_{i}^{r} \geq 0, \quad \forall i, r, \\
\mathrm{TQ}_{t i}^{r} \geq 0, \quad \forall r, i, t .
\end{gathered}
$$

The first constraint (4) establishes the assumption that the quantities of a raw material ordered at all suppliers together have to meet the needs of the production. Besides, the capacity of the chosen production method has to be able to fulfill the customers' demands as constraint (5). Constraints (6) and (7) show that the shipped quantities have to equal the ordered quantities, individually for each supplier and as a sum. Constraints (8), (9), and (10) display the capacity limits of the suppliers and the transportation modes. Moreover, the production method variable can only take a value of 0 or 1 , which is the constraint (11). The other two decision variables must be nonnegative, which is shown in constraints of (12) and (13).

\section{Solution Method}

Now that we have compiled all the objectives and constraints, the solution method can be studied more thoroughly. As introduced in the literature review section, the weighted sum model will be used to solve the multiobjective optimization problem. The weighted sum model has the following general form [33]:

$$
\begin{gathered}
\min \quad \sum_{i=1}^{k} w_{i} f_{i}(x) \\
\text { with } w_{i} \geq 0, \quad \forall i \\
\sum_{i=1}^{k} w_{i}=1 .
\end{gathered}
$$

For our model, this general form can be reformulated into

$$
\begin{gathered}
\min \quad w_{1} F_{1}+w_{2} F_{2}+w_{3} F_{3} \\
\text { with } w_{i} \geq 0, \quad \forall i, \\
\sum_{i=1}^{3} w_{i}=1 .
\end{gathered}
$$

If the objectives, like in our case, have a different magnitude, the objective functions have to be normalized. In this case, the general form changes to [33]

$$
\begin{aligned}
& \min \quad w_{1} \theta_{1} F_{1}+w_{2} \theta_{2} F_{2}+w_{3} \theta_{3} F_{3} \\
& \text { with } w_{i} \geq 0, \quad \forall i, \\
& \sum_{i=1}^{3} w_{i}=1 .
\end{aligned}
$$

$w_{i}$ is the weight assigned by the decision maker and $\theta_{i}$ is the normalization factor. Thus, before the optimization problem can be solved, weights and normalization factors have to be computed. 
4.1. Weights Setting. There are various methods to model a decision maker's preferences into weights. One of the most famous methods is the AHP method, which was first introduced by Saaty [34]. AHP stands for analytic hierarchy process; it is a method for scaling weights of the elements in each level of a hierarchy with respect to an element (i.e., a criterion or objective) of the next higher level [35].

In order to set the weights of objectives, in our case, we assume that

(i) the economical performance (factor 1) is slightly more important than the environmental performance (factor 2) of the supply chain;

(ii) the economical performance is moderately more important than the social performance (factor 3);

(iii) the environmental performance is slightly more important than the social performance (factor 2).

Based on this assumption, the weights for the different objectives can be derived through calculating the eigenvector of the evaluation matrix (see Table 3) (the detail procedure of AHP is omitted).

According to the calculated weights, the optimization problem (17) can be established:

$$
\min 0.5396 \theta_{1} F_{1}+0.2970 \theta_{2} F_{2}+0.1634 \theta_{3} F_{3} \text {. }
$$

4.2. Normalization. Last but not least, the objective functions have to be normalized. Mausser [33] proposes three different methods of normalization:

(i) normalization by the magnitude of the objective function at the initial point $x_{0}$;

(ii) normalization by the minimum of the objective functions;

(iii) normalization by the difference of the optimal values in the Nadir and Utopia points.

Although Mausser [33] states that the normalization using the Nadir and Utopia points might render the best results, for the purpose of this paper, the more simple method of applying the minimum of the objective function will be used. As neither of the objective functions' minima will equal zero, this method is acceptable. In this case, the normalization factors will be calculated by

$$
\theta_{i}=\frac{1}{f_{i}\left(x^{[i]}\right)},
$$

where $x^{[i]}$ solves $\min _{x}\left\{f_{i}(x): x \in \Omega\right\}$.

Thus the solution function takes on the following form:

$$
\begin{aligned}
& \min 0.5396 \frac{1}{\min F_{1}} F_{1}+0.2970 \frac{1}{\min F_{2}} \\
& +0.1634 \frac{1}{\min F_{3}} F_{3} .
\end{aligned}
$$

TABLE 3: Weights for the sustainable supply chain objectives.

\begin{tabular}{lc}
\hline Objectives & Weights $\left(w_{i}\right)$ \\
\hline Economical performance & 0.5396 \\
Environmental performance & 0.2970 \\
Social performance & 0.1634 \\
& $\sum w_{i}=1$ \\
\hline
\end{tabular}

\section{Numerical Example}

After having formulated and scalarized the multiobjective optimization problem, we can now continue with testing the effectiveness of the model using example. The simulated production facility produces steel, for which the two main inputs are iron ore and coking coal. Within the time period under consideration, the steel mill has a hypothetical output of 500,000 tons of steel. It will be assumed that the site is located in Central Europe. Potential suppliers for iron ore are located in India, Brazil, and Australia, while suppliers for coking coal can be found in Australia, USA, and Canada. Those countries are, respectively, the biggest exporting nations. The possible transportation modes comprise either a combination of ship and rail or a combination of ship and truck. Last but not least, the company can choose from three different production methods, with the assumption that the first one (PM1) is the cheapest, the second one is the safest (PM2), and the third one is the most environmental friendly (PM3).

5.1. Setting Parameters. Before solving the model, we need to set parameters for the model. These parameters comprise the cost parameters, pollutant emissions parameters, injury parameters, and constraint parameters.

5.1.1. Cost Parameters. At first, the parameters constituting costs have to be established. As demonstrated in the model, costs comprise material, transportation, and production costs.

(1) Material Costs. The estimations for the material costs are based on the development of prices on the commodity exchange for iron ore and coal over the last few months [36]. For different suppliers, located in different countries, the material prices may be different. Table 4 lists estimations of prices for iron ore and coking coal depending on suppliers, that is, $C_{i}^{r}$.

(2) Transportation Costs. In our model, the transportation cost parameter $\mathrm{TC}_{t i}^{r}$ denotes the cost for transportation per kilometer of one unit raw material $r$ with transport mode $t$ from supplier $i$. For simplification, we assume that transportation costs are only related to the transportation mode. Beresford et al. [37] have investigated the prices of multimodal supply chains of iron ore between Australia and China. The prices used for our simulation were derived from their study, taking into consideration the average distance traveled by ship and the average distance traveled by rail or truck. The result is listed in Table 5. 
TABLE 4: Material prices for iron ore and coking coal $\left(C_{i}^{r}\right)$.

\begin{tabular}{lccccc}
\hline Price in \$/ton & India & Brazil & Australia & USA & Canada \\
\hline Iron ore & 120 & 130 & 140 & $\mathrm{n} / \mathrm{a}^{*}$ & $\mathrm{n} / \mathrm{a}^{*}$ \\
Coking coal & $\mathrm{n} / \mathrm{a}^{*}$ & $\mathrm{n} / \mathrm{a}^{*}$ & 130 & 140 & 150 \\
\hline
\end{tabular}

${ }^{*}$ Note: only the biggest exporting nations are taken into consideration.

TABLE 5: Transportation cost of transportation modes $\left(\mathrm{TC}_{t i}^{r}\right)$.

\begin{tabular}{lcc}
\hline Transportation mode & Ship + rail & Ship + truck \\
\hline Cost in $\$ /$ ton $/ \mathrm{km}$ & 0.0038 & 0.0037 \\
\hline
\end{tabular}

As regards the estimation of distances between the mine and the steel production facility $\left(d_{i}\right)$, for simplification, the air-line distances are used, which are listed in Table 6.

(3) Production Costs. The production cost parameters are oriented at the steel production cost model spreadsheet provided by MetalMiner [38]. At first, the depreciation of machines and equipment has to be considered. The higher the initial cost of acquisition, the higher the cost for depreciation. Besides, utility costs arise in the production processes also have to be included. Table 7 lists the parameters of depreciation of machine for different production methods, that is, $\mathrm{DP}_{m}$. Table 8 shows the utility cost per unit of product if production method $m$ is chosen, that is, $\mathrm{UC}_{m}$.

Additionally, labor costs contribute towards production costs. In a less automated production environment, more manual labor will be required (production method 1, i.e., PM1). Technical advanced production method on the other hand would reduce the labor hours required to produce a ton of product, through increased productivity (production method 3, i.e., PM3). The hourly wages will be estimated with $\$ 20$ based on German base rates for steel workers (IG Metall [39]). Table 9 shows the labor hours required to produce one unit product for three production methods.

5.1.2. Pollution Parameters. The second objective of the mathematical model is the minimization of pollution emissions, including emissions in the production and transportation.

(1) Production Emissions. The first part of supply chain pollutant emissions considered in the model is the production emissions. The base case for emissions in steel production is deduced from ThyssenKrupp's sustainability report [40] based on a German steel manufacturer. Table 10 presents the emissions for the three production methods.

(2) Transport Emissions. The second part of the supply chain significantly adding to total pollution is the transportation of iron ore and coking coal from the mines to the production site. Using average distances for sea and land haulage, the following data are concluded from Dekker et al. [11] estimation of average transportation emission. Table 11 shows the emission in different transportation methods.

5.1.3. Injury Parameters. The third part of the objective function is the social objective, which is modeled as injury/illness
TABLE 6: Supplier distance to production facility $\left(d_{i}\right)$.

\begin{tabular}{lccccc}
\hline Supplier location & India & Brazil & Australia & USA & Canada \\
\hline Distance in km & 6700 & 10500 & 17500 & 7000 & 7100 \\
\hline
\end{tabular}

TABle 7: Depreciation of machines $\left(\mathrm{DP}_{m}\right)$.

\begin{tabular}{lccc}
\hline Production method & PM1 & PM2 & PM3 \\
\hline Depreciation in \$/ton & 15 & 25 & 25 \\
\hline
\end{tabular}

TABLE 8: Utility costs in steel production $\left(\mathrm{UC}_{m}\right)$.

\begin{tabular}{lccc}
\hline Production method & PM1 & PM2 & PM3 \\
\hline Utility cost in \$/ton & 4 & 7 & 5 \\
\hline
\end{tabular}

TABLE 9: Labor hours required to produce one ton of steel $\left(H_{m}\right)$.

\begin{tabular}{lccc}
\hline Production method & PM1 & PM2 & PM3 \\
\hline Labor hours in h/ton & 0.5 & 0.48 & 0.49 \\
\hline
\end{tabular}

TABLE 10: Steel production emissions $\left(A_{m}^{p}\right)$.

\begin{tabular}{lccc}
\hline Emission in g/ton & PM1 & PM2 & PM3 \\
\hline $\mathrm{CO}_{2}$ & 566513.52 & 550289.87 & 509198.9 \\
$\mathrm{NO}_{x}$ & 518.15 & 499.9 & 489.05 \\
$\mathrm{PM}^{*}$ & 167.75 & 167.75 & 160.07 \\
\hline
\end{tabular}

Note: ${ }^{*}$ particulate matter.

TABLE 11: Emissions in different transportation modes $\left(A_{t}^{p r}\right)$.

\begin{tabular}{lcc}
\hline Emission in g/ton/km & Ship + rail & Ship + truck \\
\hline $\mathrm{CO}_{2}$ & 7.898 & 9.842 \\
$\mathrm{SO}_{x}$ & 0.2161 & 0.2114 \\
$\mathrm{NO}_{x}$ & 0.1357 & 0.1328 \\
\hline
\end{tabular}

number incidence rate. Due to a lack of nominal figures in this field, the numbers themselves are pure assumptions. But certain guidance about the average injury incidence figure was provided by ThyssenKrupp's sustainability report [40] and the BLS figures (Bureau of Labor Statistics, [41]) for the steel industry. Table 12 specifies the injury classes and the respective number of injuries/illnesses for different production methods.

5.1.4. Constraint Parameters. We now set parameters for the constraints. Production capacity $\left(\mathrm{PCA}_{m}\right)$ is set at $1,000,000$ tons for the assessed period. All other constraint parameters are presented in Tables 13, 14, and 15.

In the model, it is assumed that the transportation capacities of different suppliers for different raw materials are the same for the same transportation mode, as the density of iron ore and coking coal is very similar. Thus, we only list the transportation capacities for different transportation modes in Table 15.

5.2. Model Solutions. The model is mixed integer linear problem with integer variable $\mathrm{PM}_{m}$, continuous variables $Q_{i}^{r}$ 
TABLE 12: Injuries according to severity $\left(I_{m}^{n}\right)$.

\begin{tabular}{lccc}
\hline Severity $(n)$ & \multicolumn{3}{c}{ Production method $(m)$} \\
\hline 1 & PM1 & PM2 & PM3 \\
2 & 20 & 17 & 18 \\
3 & 6 & 5 & 5 \\
4 & 3 & 2 & 2 \\
5 & 2 & 1 & 2 \\
6 & 1 & 1 & 1 \\
7 & 1 & 0 & 1 \\
\hline
\end{tabular}

Note: the severity classes from 1 to 7 have been defined in Table 1 .

TABLE 13: Usage of iron ore and coal in production $\left(U_{m}^{r}\right)$.

\begin{tabular}{llll}
\hline Usage in ton/ton & PM1 & PM2 & PM3 \\
\hline Iron ore & 1.765 & 1.766 & 1.763 \\
Coking coal & 0.696 & 0.697 & 0.695 \\
\hline
\end{tabular}

TABLE 14: Capacities of different suppliers $\left(\mathrm{SCA}_{i}^{r}\right)$.

\begin{tabular}{lccccc}
\hline Capacity in: 1000 ton & India & Brazil & Australia & USA & Canada \\
\hline Iron ore & 100 & 500 & 600 & 0 & 0 \\
Coking coal & 0 & 0 & 200 & 100 & 200 \\
\hline
\end{tabular}

and $\mathrm{TM}_{t i}^{r}$, the Solver type is Branch and Bound Solver of LINGO 12.0. Global optimization solution is obtained in 3 seconds CPU time at the computer configuration as: Intel Core i7-2600CPU, 3.4 GHz, 4.00 RAM, and 32 bit operation system. For solving the model, it has to be run independently for each objective to compute the minima for normalization (5.1, 5.2, and 5.3).

$$
\begin{aligned}
& \min F_{1}=236,728,200 ; \\
& \min F_{2}=370783.8 \text { (emissions are scaled in tons); } \\
& \min F_{3}=4.980914 .
\end{aligned}
$$

Using the proposed multiobjective optimization model, the production facility's optimal decision would be to choose production method PM2. Raw materials order quantities from difference suppliers are presented in Table 16 and the shipped quantities of transportation modes are displayed in Table 17.

Those solutions for the decision variables will lead to total costs of $\$ 243,701,800$ (cost per ton of steel $\$ 487.4$ ). Furthermore a total of $391,699.5$ tons of pollutants are emitted, with production accounting for $275,478.8$ tons and transportation for $116,220.8$ tons. The injury and illness incidence rate will be equal to 4.879263 .

5.3. Discussion of Results. First and foremost, the results of the numerical example show that the constructed model is indeed feasible and effective. This is the most important finding. Beyond that, one can draw even more conclusions from the solutions.

Firstly, it is revealed that a multiobjective optimization approach presents different results from the single objective
TABLE 15: Capacities of different transportation modes $\left(\mathrm{TCA}_{t i}^{r}\right)$.

\begin{tabular}{lcc}
\hline Transportation mode & Ship + rail & Ship + truck \\
\hline Capacity in ton & 400,000 & 100,000 \\
\hline
\end{tabular}

TABLE 16: Order quantities of iron ore and coking coal from the different suppliers.

\begin{tabular}{lccccc}
\hline $\begin{array}{l}\text { Order quantities in } \\
\text { ton }\end{array}$ & India & Brazil & Australia & USA & Canada \\
\hline Iron ore & 100,000 & 500,000 & 283,000 & 0 & 0 \\
Coking coal & 0 & 0 & 48,000 & 100,000 & 200,000 \\
\hline
\end{tabular}

functions alone. For example, production method PM1 is chosen when the economic objective $\left(F_{1}\right)$ is minimized independently. However, when the multiple objective optimization model is applied, production method PM2 is identified as the optimal production method. The same outcome can be found when examining the shipped quantities. If only costs are considered, the truck will be chosen much more frequently. If the environmental performance is added to the model, on the contrary, railway transportation becomes the favourable option (see Table 17).

Secondly, one can learn from the results that a multiobjective optimization model makes it possible for companies to accept reasonably higher costs, if other factors are taken into consideration. Hence, the minimum of costs is at $\$ 236,728,200$, but the final amount of money spent in the supply chain equals an amount of $\$ 243,701,800$. Those slightly higher costs are the price one has to pay for a safer and more ecological production and transportation. Still, if the costs would rise enormously, making the company economical uncompetitive, the bad economic performance would outweigh the other factors and the multiple objective optimization model would compute different results. This is the consequence of the simultaneous consideration of all three dimensions.

Lastly, the numerical example enlightens the importance of the social dimension. As mentioned before, corporate social responsibility has widely been neglected in operational research literature so far. Incorporating the employee safety into the multiple objective optimization model leads to a surprising result. Through the exponential function, production methods, such as PM1, that have a higher risk of fatalities or severe injuries, become unacceptable. Even production method PM3, which produces much less emissions, is unfavourable compared to PM2. Due to a better incidence rate on the one hand (compared to PM1 and PM3) and lower costs on the other hand (compared to PM3), PM2 is chosen in the multiple objective optimization model. Hence, clearly the constructed model adds information to a company's decisions and can therefore reach different results, which can lead to improved supply chains from a sustainability perspective.

\section{Conclusion}

Sustainable supply chain has become one important operations strategy for corporate competition, especially for 
TABLE 17: Raw material quantities shipped via different transportation modes.

\begin{tabular}{lcccc}
\hline Shipped quantities in ton & Iron ore & \multicolumn{2}{c}{ Coking coal } \\
India & Ship + rail & Ship + truck & Ship + rail & 0 \\
Brazil & 100,000 & 0 & 0 & 0 \\
Australia & 400,000 & 100,000 & 48,500 & 0 \\
USA & 283,000 & 0 & 100,000 & 0 \\
Canada & 0 & 0 & 200,000 & 0 \\
\hline
\end{tabular}

large international corporations. Many firms have an annual report of CSR (corporate social responsibility). Under this background, it is necessary to incorporate CSR into supply chain optimization model. This paper addresses this problem, incorporates the three pillars of sustainability-economic, environmental, and social dimensions-into a supply chain optimization model. The purpose is to give supply chain managers a tool for decision making that is not only based on reducing costs or maximizing profit but also focuses on environmental protection and social responsibility. Research result shows that this idea is feasible.

Naturally, there are also certain deficiencies in the model, mainly resulting from the limited scope of the work. Some improvement works can be done to enhance the application value of the model. Firstly, more metrics for each of the dimensions might be considered to better reflect the reality. Also the model might be extended to accommodate more than one period and/or uncertainty in demand. From a mathematical viewpoint, testing different multiobjective solution methods might lead to better or more reliable results, as the weighted sum model yields problems, if nonconvex Pareto curves exist. Further enhancements could be made by using the difference of Nadir and Utopia point to normalize the objective functions.

Despite the described shortcomings, the existing simple model has already been proven to be effective. The program has shown that including different criteria might lead to changes in making choices. For example, when only considering costs, production method PM1 would have been chosen. But when the model also comprises the other two dimensions, production method PM2 is selected. Thus, including sustainability criteria into a company's decision making is not extremely arduous or unrealistic. Considering the pressure from environment and society, corporations should make amends to their existing decision support systems. Bearing in mind new governmental regulations, the cost of climate change or the increasing awareness of customers of environmental protection and social responsibility, corporations should give up a pure focus on profit maximization. In the long-run, sustainable supply chain models will certainly pay off, even though it might initially involve expensive investments. As introduced in the literature review, multiobjective optimization is able to process more information than a conventional single-objective method. Thus, using multicriteria decision model might eventually lead to improved choices. A multiobjective model like the one introduced in this paper can provide guidance to supply chain managers in a time when circumstances are changing quickly.

\section{Conflict of Interests}

The authors declare that there is no conflict of interests regarding the publication of this paper.

\section{Acknowledgment}

This paper is funded by NSFC (Grant no. 71372154).

\section{References}

[1] M. Sahlin, "Advancing sustainable development in Sweden," in Institutionalizing Sustainable Development, chapter 1, pp. 15-17, OECD, Paris, France, 2007.

[2] T. Strange and A. Bayley, Sustainable Development: Linking Economy, Society, Environment, OECD Insights, OECD Publishing, 2008.

[3] E. Salim, “The paradigm of sustainable development," in Institutionalizing Sustainable Development, chapter 3, pp. 25-30, OECD, Paris, France, 2007.

[4] DARA, Climate Vulnerability Monitor, 2nd edition, 2013, https://s3.amazonaws.com/daraint/CVM2ndEd-ExecutiveSummary.pdf.

[5] Á. Halldórsson, H. Kotzab, and T. Skjøtt-Larsen, "Supply chain management on the crossroad to sustainability: a blessing or a curse?" Logistics Research, no. 2, pp. 83-94, 2009.

[6] European Commission, The EU Emissions Trading System (EU ETS), European Union, 2013, http://ec.europa.eu/clima/publications/docs/factsheet_ets_2013_en.pdf.

[7] ARD, “Der Preis der Blue-Jeans," [TV report], 2012, http:// mediathek.daserste.de/sendungen_a-z/799280_reportage-dokumentation/11398300_der-preis-der-blue-jeans.

[8] F. Willershausen, "Die Modelüge-wie deutsche Firmen produzieren lassen," Wirtschaftswoche, 2012, http://www.wiwo .de/unternehmen/industrie/textilindustrie-die-modeluege-wiedeutsche-firmen-produzieren-lassen/7162224.html.

[9] C. Duhigg and D. Barboza, "In China, human costs are built into an iPad," The New York Times, 2013, http://www.nytimes .com/2012/01/26/business/ieconomy-apples-ipad-and-the-humancosts-for-workers-in-china.html?pagewanted=all.

[10] China Daily, "Real cause of tragedy," China Daily, 2013, http://europe.chinadaily.com.cn/opinion/2012-11/21/content_15946621.htm.

[11] R. Dekker, J. Bloemhof, and I. Mallidis, "Operations research for green logistics-an overview of aspects, issues, contributions and challenges," European Journal of Operational Research, vol. 219, no. 3, pp. 671-679, 2012. 
[12] R. Jamshidi, S. Ghomi, and B. Karimi, "Multi-objective green supply chain optimization with a new hybrid memetic algorithm using the Taguchi method," Scientia Iranica, vol. 19, no. 6, pp. 1876-1886, 2012.

[13] A. Nagurney and L. S. Nagurney, "Sustainable supply chain network design: a multicriteria perspective," International Journal of Sustainable Engineering, vol. 3, no. 3, pp. 189-197, 2010.

[14] T. Paksoy, E. Özceylan, and G. Weber, "A multi objective model for optimization of a green supply chain network," Global Journal of Technology and Optimization, no. 2, pp. 84-96, 2011.

[15] S.-C. Tseng and S.-W. Hung, "A strategic decision-making model considering the social costs of carbon dioxide emissions for sustainable supply chain management," Journal of Environmental Management, vol. 133, no. 15, pp. 315-322, 2014.

[16] L. J. Zeballos, C. A. Méndeza, A. P. Barbosa-Povoab, and A. Q. Novais, "Multi-period design and planning of closed loop supply chains with uncertain supply and demand," Computers and Chemical Engineering. In press.

[17] J. M. Cruz, "Dynamics of supply chain networks with corporate social responsibility through integrated environmental decision-making," European Journal of Operational Research, vol. 184, no. 3, pp. 1005-1031, 2008.

[18] Y. Bouchery, A. Ghaffari, Z. Jemai, and Y. Dallery, "Including sustainability criteria into inventory models," European Journal of Operational Research, vol. 222, no. 2, pp. 229-240, 2012.

[19] C. R. Carter and D. S. Rogers, "A framework of sustainable supply chain management: moving toward new theory," International Journal of Physical Distribution and Logistics Management, vol. 38, no. 5, pp. 360-387, 2008.

[20] A. Ait-Alla, M. C. Teucke, M. Lütjen, S. Beheshti-Kashi, and H. R. Karimi, "Robust production planning in fashion apparel industry under demand uncertainty via conditional value-atrisk," Mathematical Problems in Engineering, vol. 2014, Article ID 901861, 2014.

[21] H. R. Karimi, N. A. Duffie, and S. Dashkovskiy, "Local capacity Ho control for production networks of autonomous work systems with time-varying delays," IEEE Transactions on Automation Science and Engineering, vol. 7, no. 4, pp. 849-857, 2010.

[22] A. Mehrsai, H. R. Karimi, K. D. Thoben, and B. Scholz-Reiter, "Using metaheuristic and fuzzy system for the optimization of material pull in a push-pull flow logistics network," Mathematical Problems in Engineering, vol. 2013, Article ID 359074, 19 pages, 2013.

[23] A. Mehrsai, H.-R. Karimi, and B. Scholz-Reiter, "Toward learning autonomous pallets by using fuzzy rules, applied in a Conwip system," International Journal of Advanced Manufacturing Technology, vol. 64, no. 5-8, pp. 1131-1150, 2013.

[24] W. Bretzke and K. Barkawi, Nachhaltige Logistik-Antworten Auf Eine Globale Herausforderung, Springer, Berlin, Germany, 2010.

[25] World Commission on Environment and Development, Our Common Future, Oxford University Press, New York, NY, USA, 1987.

[26] J. Elkington, Cannibals with Forks: The Triple Bottom Line of 21stcentury Business, New Society Publishers, 1998.

[27] T. Dyllick and K. Hockerts, "Beyond the business case for corporate sustainability," Business Strategy and the Environment, vol. 11, no. 2, pp. 130-141, 2002.

[28] C. Tang and S. Zhou, "Research advances in environmentally and socially sustainable operations," European Journal of Operational Research, no. 3, pp. 585-594, 2012.
[29] B. Cetinkaya, R. Cuthbertson, G. Ewer, T. Klaas-Wissing, W. Piotrowicz, and C. Tyssen, Sustainable Supply Chain Management_Practical Ideas for Moving Towards Best Practice, Springer, Berlin, Germany, 2011.

[30] F. Székely and M. Knirsch, "Responsible leadership and corporate social responsibility: metrics for sustainable performance," European Management Journal, vol. 23, no. 6, pp. 628-647, 2005.

[31] S. E. Daniel, D. C. Diakoulaki, and C. P. Pappis, "Operations research and environmental planning," European Journal of Operational Research, vol. 102, no. 2, pp. 248-263, 1997.

[32] Bureau of Labor Statistics, Incidence Rates of Nonfatal Occupational Injuries and Illnesses By Industry and Case Types, Bureau of Labor Statistics, Washington, DC, USA, 2011, http://www.bls.gov/iif/oshsum.htm\#11Summary\%20Tables.

[33] H. Mausser, "Normalization and other topics in multi-objective optimization," in Proceedings of the Fields-MITACS Industrial Problems Workshop, O. Grodzevich and O. Romanko, Eds., pp. 89-101, 2006.

[34] T. L. Saaty, The Analytic Hierarchy Process, McGraw-Hill, New York, NY, USA, 1980.

[35] T. L. Saaty, "A scaling method for priorities in hierarchical structures," Journal of Mathematical Psychology, vol. 15, no. 3, pp. 234-281, 1977.

[36] indexmundi, "Iron Ore Monthly Price," 2013, http://www .indexmundi.com/commodities/?commodity=iron-ore.

[37] A. Beresford, S. Pettit, and Y. Liu, "Multimodal supply chains: iron ore from Australia to China," Supply Chain Management, vol. 16, no. 1, pp. 32-42, 2011.

[38] MetalMiner, "Steel Production Cost Model," 2009, http:// agmetalminer.com/steel-production-cost-model.

[39] IG Metall, "Tariflöhne: Eisen- und Stahlindustrie," http://www .igmetall.de/cps/rde/xchg/internet/style.xsl/eisen-und-stahl-loehne-und-gehaelter-913.htm.

[40] ThyssenKrupp, "Nachhaltigkeitsbericht 2009, Duisburg: ThyssenKrupp Steel AG," 2009, http://www.econsense.de/sites/ all/files/TKS_NH-Bericht_2009_dt_0.pdf.

[41] Bureau of Labor Statistics, "How to Compute a Firm's Incidence Rate for Safety Management," 2012, http://www.bls.gov/ iif/osheval.htm. 


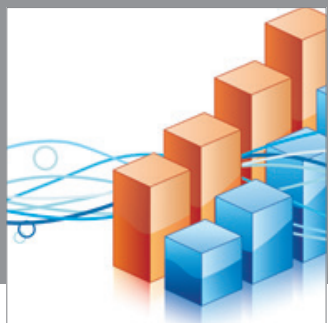

Advances in

Operations Research

mansans

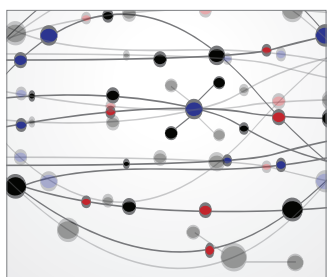

The Scientific World Journal
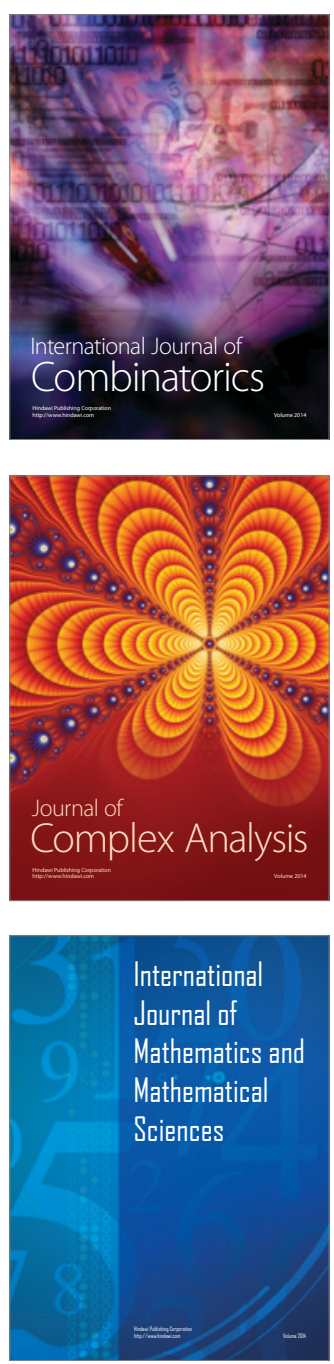
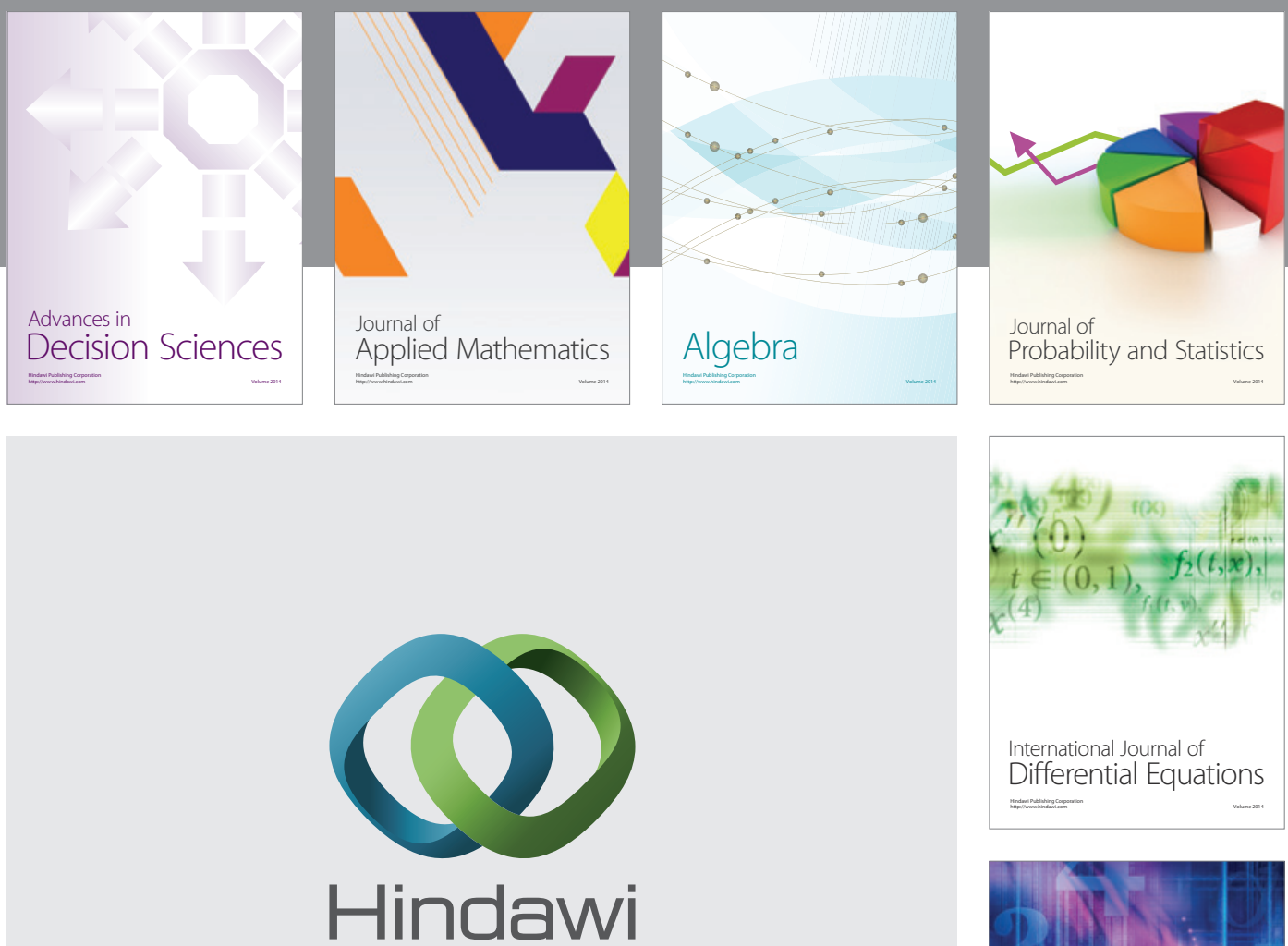

Submit your manuscripts at http://www.hindawi.com
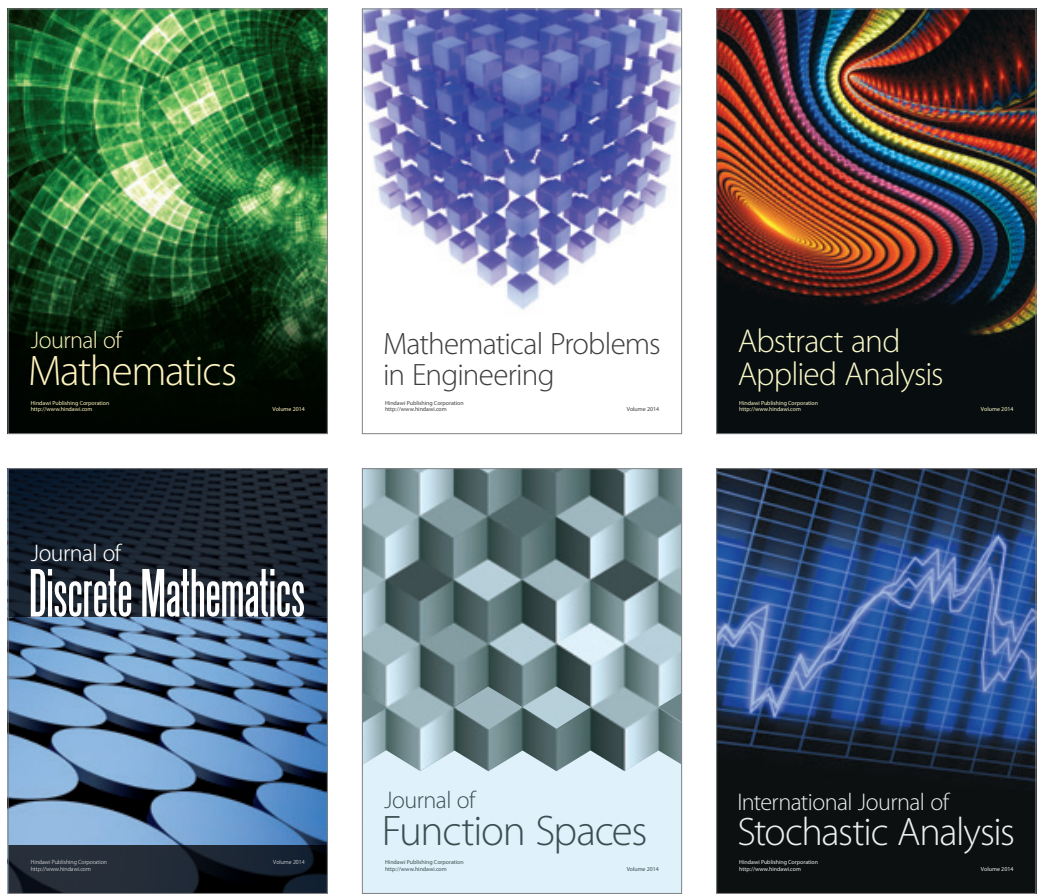

Journal of

Function Spaces

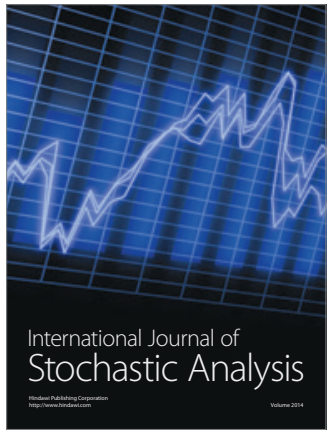

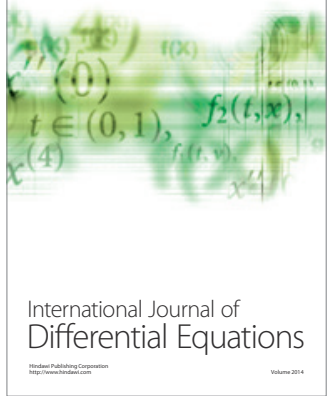
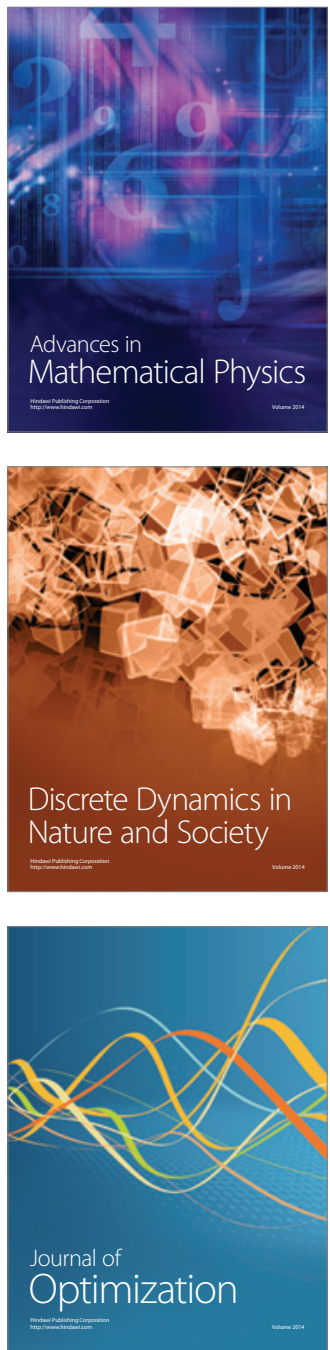